Research Square
Preprints are preliminary reports that have not undergone peer review.

They should not be considered conclusive, used to inform clinical practice, or referenced by the media as validated information.

\title{
Protocatechuic Acid, Ferulic Acid and Relevant Defense Enzymes Correlate Closely with Walnut Resistance to Xanthomonas arboricola pv. Juglandis
}

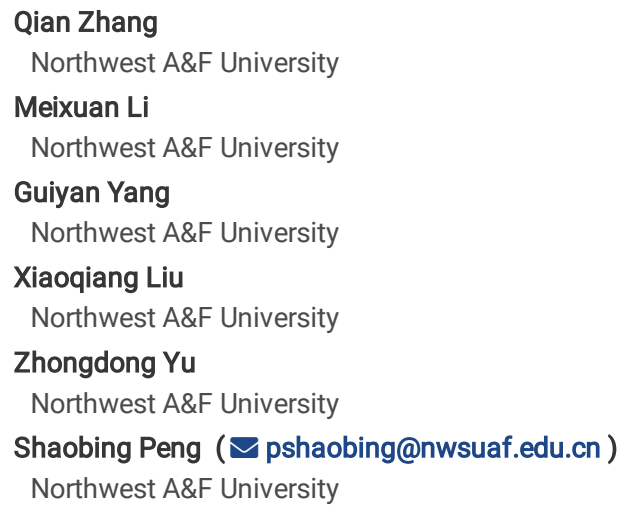

Research Article

Keywords: Juglans regia L., Xanthomonas, disease resistance, defense enzyme, phenolic compounds

Posted Date: February 17th, 2022

DOI: https://doi.org/10.21203/rs.3.rs-1316810/v1

License: (c) (1) This work is licensed under a Creative Commons Attribution 4.0 International License. Read Full License 


\section{Abstract}

Background: Juglans regia L. is an important nut tree that has a wide range of distribution in temperate regions of the world. In some walnut orchards, walnut blight can become a problematic disease that affects the growth of walnut trees. To explore the correlation between biochemical response and walnuts resistance, we inoculated four walnut cultivars with Xanthomonas arboricola pv. Juglandis (abv. Xaj). The walnut cultivars were, namely, 'Xiangling', 'Xiluo 2', 'Yuanfeng' and 'Xifu 2'. Total phenol content (TPC) and total flavonoid content (TFC) were measured, whereby nine major phenolic compounds and several relevant enzymes were identified.

Results: The results showed that the most resistant and susceptible walnut varieties were 'Xiluo 2' and 'Xifu 2' respectively. The reaction of walnut to Xanthomonas arboricola pv. Juglandis was characterized by the early accumulation of phenolic compounds in the infected site. The accumulation of phenolic compounds after infection was accompanied by an increase in reactive oxygen species (ROS). This was reflected in the catalytic effect of peroxidase (POD) on ferulic acid dimerization which contributed to walnut resistance against disease. This also meant a series of defense-related functions with a key role of polyphenol oxidase (PPO). The results revealed that the competitiveness of flavonoids were weakened in biosynthesis, thereby strengthening the synthesis of chemicals catalyzed by phenylalanine ammonia lyase (PAL) against walnut blight. The resistant variety 'Xiluo 2' had a significantly higher protocatechuic acid content, compared to other varieties, when measured on the 4th day after inoculation (dpi).

Conclusion: Our findings confirmed that walnut blight resistance is a collective function of interactions between the accumulation of phenolic compounds in the phenylpropane metabolic pathway and the action of relevant defense enzymes.

\section{Introuction}

Juglans regia $\mathrm{L}$. is one of the most important economic tree species of the Juglandaceae family. Walnut is cultivated worldwide for its delicious taste and rich nutritional qualities, with its protein and protein hydrolysates that play an important role in promoting health[1]. Among the pathogens that affect walnut, there is a species of bacteria, namely, Xanthomonas arboricola pv. Juglandis (abv. Xaj), which causes walnut blight. It is particularly damaging in wet years and on early leafing cultivars, as it poses a serious threat to walnut growth and production. It can enter through stomata, lenticels, and stigmas, and then spread by the wind and rain, or by insects and agricultural operations [2-5]. The occurrence of Xanthomonas has reportedly affected rice [6], citrus [7], walnut and other plants. To date, the control of walnut blight disease has relied on copper-based biocides [8]. Nonetheless, biocides may be overlooked because of their toxicity, their impact on the environment and on natural ecosystems [9]. The most economical, effective measure for the control of this disease is to cultivate blightresistant walnut cultivars.

Plant resistance can be classified into two categories: constitutive resistance and inducible resistance. Constitutive resistance is an inherent trait that relies on epidermal wax, cell walls, and cuticles [10-11]. Inducible resistance, on the other hand, refers to a set of induced defense responses evolved by plants as a result of pathogen stimulation, whereby pathogens are resisted by plants through better mechanisms of defense. This active defense-response can strengthen the endogenous defense ability of plants which comprises the accumulation of ROS, rapid changes in the biochemical features of cell walls and the enhancement of various defense-related enzyme activities [12]. The interactions between walnuts and disease involve the coordination of ROS and other signals, as these are dependent on stress-specific chemicals that initiate self-protective responses in neighboring cells [13]. ROS plays a protective role at times of infection by reinforcing the cell walls of the host plant to inhibit pathogenic growth [14]. Previous works have summarized that plants respond to pathogenic attack by staging a transient burst of ROS which triggers a chain of reactions that promote walnut defense against pathogens [15]. RBOHs are a major reactive oxygen species that contribute greatly to the scavenging system. Specifically, it transfers electrons from the NADPH in the cytosolic fluid to oxygen in the apoplast (i.e. the main source of ROS) in order to generate superoxide anion $\left(\mathrm{O}_{2}{ }^{-}{ }^{-}\right.$). The latter is then converted to $\mathrm{H}_{2} \mathrm{O}_{2}$, either spontaneously or by SOD. As SOD produces $\mathrm{H}_{2} \mathrm{O}_{2}$, the disproportionate amount of $\mathrm{H}_{2} \mathrm{O}_{2}$ is then degraded by POD and CAT into non-toxic $\mathrm{H}_{2} \mathrm{O}_{2}$ and oxygen, thereby protecting plant cells from serious oxidative damage $[13,15]$.

Phenols are a pervasive group of secondary metabolites in plants [16]. Gallic acid, ferulic acid and quercetin are different types of phenolic chemicals in walnuts [17]. Phenolic chemicals comprise a part of inducible resistance. In plant defense, phenolic compounds can act as physical or chemical barriers against pathogenic invasion. Previous research indicated a strong linear relationship between phenolic compounds in walnut microshoots and antioxidant activity [18]. Moreover, a detailed research on plant-pathogen interactions revealed that these phenolic compounds are generated through the phenylpropanoid metabolic pathway, with the first reaction being catalyzed by PAL. It can accumulate significantly to participate in the defense process when pathogens invade the host [19]. Infection of maize cultivars with Dickeya zeae enhanced PAL activity more in inducing resistance among tolerant cultivars, compared to susceptible ones [20]. PAL can be used as a precursor for creating metabolites such as phenylpropanoids, flavonoids, and cell wall lignin that are synthesized to take part in the resistance against pathogens [21-22]. PPO has been observed to have roles in the phenylpropane pathway. It is a copper-containing enzyme that inhibits pathogens by converting monophenols into o-catechol compounds with oxygen as a substrate. As pathogens destroy plant cells, phenol oxidation occurs by PPO and pathogenic toxicity [23].

Identification and utilization of disease resistance may provide a basis for a feasible control strategy for walnut blight. Although walnuts are rich in phenolic compounds, the potential for disease resistance by phenolic chemicals is not fully understood. Therefore, the changes of activities in defense enzymes were studied in the process of infection in this study. In addition, HPLC can detect differences in the phenolic metabolism of different walnut cultivars after infection. This study provided valuable physiological information for understanding the response of walnut to Xanthomonas, and revealed how relevant defense-related enzymes and chemicals can be important in the resistance against blight disease, thereby hinting at possible ways into the breeding of resistant cultivars.

\section{Results}




\section{Effects of treatments on the four walnut cultivars}

Walnut trees were detected with blight disease and all cultivars were infected with Xanthomonas. Accordingly, the selected cultivars had different levels of susceptibility (Table 1). Blight disease was most prevalent (by more than $85 \%$ ) in each cultivar on the 16th day dpi (Fig. 1). Fruit rot and blackening were recurrent symptoms in all four cultivars at $16 \mathrm{dpi}$, although the sizes of lesions varied. The average diameter of lesions on the fruits of each treatment was used as a measure of walnut resistance against pathogenic activity. On the 16th dpi, the difference of lesion size between 'Xiluo 2' and 'Xifu 2' was the largest, meaning that 'Xifu 2' was the most susceptible, whereas 'Xiluo 2' was the most resistant (Fig. 2).

Table 1

The disease index and resistance evaluation of different cultivars to walnut blight

\begin{tabular}{|lll|}
\hline Cultivar & Disease index & Resistance \\
\hline Xiangling & $41.35 \pm 2.87^{\mathrm{b}}$ & Moderate susceptibility \\
\hline Xluo 2 & $23.69 \pm 3.15^{\mathrm{c}}$ & Resistance \\
\hline Yuanfeng & $38.07 \pm 3.21^{\mathrm{b}}$ & Moderate resistance \\
\hline Xifu 2 & $57.67 \pm 2.33^{\mathrm{a}}$ & Susceptibility \\
\hline
\end{tabular}

\section{Antioxidant Activity}

After inoculation with the pathogen, SOD activity increased in the outset but then decreased. This pattern of change was observable in all four cultivars. On day 0 , the SOD activity of all cultivars that were infected with the pathogen was significantly lower than that of the control. Four days after inoculation, the SOD activity staged an obvious increase. The growth rates of 'Xiangling' and 'Xiluo 2' reached $93 \%$ and $97 \%$, respectively, whereas those on 'Yuanfeng' and 'Xifu 2' reached $108 \%$ and $158 \%$, respectively. The activity of SOD, after infection with the pathogen, began to decrease rapidly and was significantly lower than that of the control on the 8th day. In terms of the SOD level on the 16th day, there was no significant difference between the control and the inoculated samples of three cultivars, except that the SOD in 'Xiluo 2' was significantly higher than that of the control (Table 2).

Table 2

SOD Activity $\left(\mathrm{U} \cdot \mathrm{g}^{-1} \mathrm{FW} \cdot \mathrm{h}^{-1}\right)$

\begin{tabular}{|llllllll}
\hline $\begin{array}{l}\text { Days after } \\
\text { treatments }\end{array}$ & Xiangling & & Xluo 2 & & Yuanfng & \\
\cline { 2 - 7 } & CK & Xaj & CK & Xaj & CK & Xaj & CK \\
\hline Od & $1168.28 \pm 2.39^{\mathrm{d}}$ & $911.82 \pm 10.36^{\mathrm{e}}$ & $1379.31 \pm 11.15^{\mathrm{d}}$ & $1002.30 \pm 42.95^{\mathrm{e}}$ & $1175.17 \pm 41.22^{\mathrm{d}}$ & $917.70 \pm 100.10^{\mathrm{e}}$ & $1029.89 \pm 64.06^{\mathrm{d}}$ \\
\hline $4 \mathrm{~d}$ & $1364.60 \pm 25.91^{\mathrm{c}}$ & $1762.76 \pm 12.65^{\mathrm{a}}$ & $1609.20 \pm 96.35^{\mathrm{c}}$ & $1976.09 \pm 48.24^{\mathrm{a}}$ & $1526.44 \pm 66.02^{\mathrm{c}}$ & $1913.20 \pm 15.14^{\mathrm{a}}$ & $1338.85 \pm 166.52^{\mathrm{c}}$ \\
\hline $8 \mathrm{~d}$ & $1558.62 \pm 28.68^{\mathrm{b}}$ & $1346.21 \pm 5.75^{\mathrm{c}}$ & $1919.54 \pm 37.39^{\mathrm{a}}$ & $1674.48 \pm 27.92^{\mathrm{bc}}$ & $1671.72 \pm 6.37^{\mathrm{bc}}$ & $1501.61 \pm 44.28^{\mathrm{c}}$ & $1576.09 \pm 7.19^{\mathrm{ab}}$ \\
\hline $16 \mathrm{~d}$ & $1515.40 \pm 41.56^{\mathrm{b}}$ & $1533.79 \pm 42.25^{\mathrm{b}}$ & $1627.68 \pm 35.06^{\mathrm{c}}$ & $1768.37 \pm 6.37^{\mathrm{b}}$ & $1609.20 \pm 41.59^{\mathrm{bc}}$ & $1820.30 \pm 128.30^{\mathrm{ab}}$ & $1439.08 \pm 19.92^{\mathrm{bc}}$ \\
\hline
\end{tabular}

Note. Table 1represents the SOD activity in the control (CK) and walnut fruits infected Xaj treated for 0-16 days. The data are expressed as mean \pm standard indicated significant differences at a level of $p<0.05$.

The changes in CAT activity were different in each of the four cultivars. 'Xiangling' had no significant changes in its CAT activity throughout the whole infection process. CAT activities in the other three cultivars were basically close to the control samples after inoculation. Nonetheless, they differed from each other, depending on the stage of pathogenic development. On the 8th dpi, the CAT activity in 'Xiluo 2' was significantly higher than in the control, whereas differences in the CAT activities of 'Xifu 2' and 'Yuanfeng', occurring between the inoculated fruits and the control fruits of each cultivar, were observed on the 16th day. Meanwhile, the CAT activity of 'Yuanfeng' was higher than that of 'Xifu 2'. Ultimately, the pathogen caused differences in CAT activity when comparing the cultivars (Fig. 3).

POD activity increased in all cultivars after inoculation. This increase reached $180 \%$ in the case of 'Xiangling', as a result of infection with the pathogen, whereas it increased by $120 \%$ in the resistant cultivar 'Xiluo 2'. At the same time, POD activity in 'Yuanfeng' and 'Xifu 2' increased by $140 \%$ and $96 \%$, respectively. On the 16th dpi, POD activity in 'Xiluo 2' was significantly higher than that of the control. In fruits of the remaining three cultivars, infected samples had no significant difference compared with the control samples in this regard (Fig. 4).

\section{Pal Activity Analysis}

PAL activity initially decreased and then increased after inoculation. On the 4th dpi, PAL activity decreased in all cultivars and, in particular, it decreased in 'Xifu 2 ' by nearly 2-fold. At 8 dpi, an obvious increase in PAL activity was observed, with significant levels of activity in 'Xiluo 2' as a disease-resistant cultivar, compared to the control. Meanwhile, there were negligible differences in other cultivars. Sixteen days after inoculation, PAL activity decreased rapidly in 'Xiluo 2 ' and was very close to that of the control. Inoculated samples of 'Yuanfeng' and 'Xifu 2' showed significant levels of PAL activity, compared to the control. In the 'Xiangling' cultivar, no notable change occurred in the late stages of disease development (Fig. 5). 


\section{Ppo Activity Analysis}

Similar to other enzyme activities, PPO took a trend of increase in activity, but with variable intensities among the cultivars. The PPO in 'Xiangling', 'Yuanfeng' and 'Xifu 2' changed very little if any, compared to the control on the 8th day. However, the PPO activity in inoculated fruits was significantly higher than that of the control on the 16th day. A marked difference was observed between 'Xiluo 2' and other cultivars. At 4 and 8 dpi, the PPO activity of the control fruits was significantly higher than that of the inoculated samples. On the 16th day, inoculated samples of 'Xiluo 2 ' showed significantly higher PPO activity, compared to the control group of 'Xiluo 2 ' and other cultivars as well (Fig. 6).

\section{Phenolic Chemical Content Analysis}

\section{Changes in the content of TPC and flavonoids TFC}

Similar to POD and PPO, the TPC showed an upward trend in value among all cultivars. Phenolic contents increased in 'Xiangling' on the 4th day, while the TPC of inoculated fruits was significantly higher than that of the control. Even though it decreased slightly on the 8th day, the TPC in inoculated fruits was still significantly higher than that of the control. By the 16th day, the TPC increased rapidly and reached a maximum value, so that phenolic contents in control samples were significantly higher than those in inoculated samples. At 4 dpi, TPC increased rapidly in inoculated 'Xiluo 2' and became significantly different from that of the control. The TPC decreased slightly on the 8th day after inoculation and showed no significant difference compared to the control. Also, no changes were observed between 'Yuanfeng' and 'Xifu 2' in terms of TPC throughout the experiment (Table 3).

Table 3

The content of TPC $\left(\mathrm{mg} \cdot \mathrm{g}^{-1} \mathrm{FW}\right)$

\begin{tabular}{|c|c|c|c|c|c|c|c|c|}
\hline \multirow[t]{2}{*}{ Days after treatments } & \multicolumn{2}{|l|}{ Xiangling } & \multicolumn{2}{|l|}{ Xluo 2} & \multicolumn{2}{|l|}{ Yuanfng } & \multicolumn{2}{|l|}{ Xifu 2} \\
\hline & CK & Xaj & CK & Xaj & CK & Xaj & CK & Xaj \\
\hline $\mathrm{Od}$ & $22.84 \pm 1.61^{f}$ & $23.64 \pm 0.39^{f}$ & $25.21 \pm 2.90^{d}$ & $25.76 \pm 1.89^{d}$ & $27.55 \pm 2.55^{\mathrm{a}}$ & $26.66 \pm 3.83^{a}$ & $23.16 \pm 3.15^{b}$ & $22.71 \pm 5.57^{b}$ \\
\hline $4 d$ & $27.43 \pm 1.34^{\mathrm{e}}$ & $34.37 \pm 0.14^{c}$ & $29.13 \pm 0.17^{\mathrm{cd}}$ & $34.56 \pm 0.03^{b}$ & $33.42 \pm 2.86^{a}$ & $26.91 \pm 5.24^{a}$ & $26.30 \pm 6.14^{\mathrm{ab}}$ & $23.48 \pm 0.37^{b}$ \\
\hline $8 d$ & $26.87 \pm 0.03^{e}$ & $30.89 \pm 1.11^{d}$ & $27.55 \pm 0.97^{\mathrm{cd}}$ & $31.21 \pm 1.64^{\mathrm{bc}}$ & $28.39 \pm 1.91^{\mathrm{a}}$ & $34.80 \pm 0.17^{a}$ & $31.91 \pm 0.78^{\mathrm{ab}}$ & $31.53 \pm 0.39^{\mathrm{ab}}$ \\
\hline $16 d$ & $45.42 \pm 0.03^{a}$ & $42.11 \pm 1.66^{b}$ & $41.59 \pm 1.58^{\mathrm{a}}$ & $35.05 \pm 2.42^{b}$ & $33.23 \pm 4.46^{\mathrm{a}}$ & $35.12 \pm 3.57^{a}$ & $28.64 \pm 3.64^{\mathrm{ab}}$ & $37.04 \pm 5.66^{a}$ \\
\hline
\end{tabular}

Note. Table 2 represents the contents of the total phenolic compounds (TPC) in the control (CK) and walnut fruits infected Xaj treated for 0-16 days. And the values are expressed as the mean \pm standard deviation of three biological replicates. Letters indicated significant differences at a level of $p<0.05$.

The TFC in fruits also increased in response to inoculation. While evidenced in all cultivars after the treatments, the TFC increased significantly in 'Xiangling' and 'Yuanfeng' in a manner very similar to the control. Significant changes in the TFC of 'Xifu 2' occurred on the 4 th dpi. At $16 \mathrm{dpi}$, however, the value in 'Xiluo 2 ' was significantly lower than that of the control. These results suggest that flavonoids can play a significant role in different stages of disease-resistance in cultivars (Table 4).

Table 4

The content of TFC $\left(\mathrm{mg} \cdot \mathrm{g}^{-1} \mathrm{FW}\right)$

\begin{tabular}{|lllllllll}
\hline Days after treatments & Xiangling & & Xluo 2 & & Yuanfng & & Xifu 2 \\
\cline { 2 - 8 } & CK & Xaj & CK & Xaj & CK & Xaj & CK & Xaj \\
\hline Od & $3.89 \pm 0.73^{\mathrm{bc}}$ & $4.10 \pm 0.60^{\mathrm{bc}}$ & $3.96 \pm 0.53^{\mathrm{c}}$ & $3.82 \pm 0.37^{\mathrm{c}}$ & $3.59 \pm 0.39^{\mathrm{a}}$ & $3.70 \pm 0.63^{\mathrm{a}}$ & $3.11 \pm 0.44^{\mathrm{bc}}$ & $3.13 \pm 0.60^{\mathrm{bc}}$ \\
\hline $4 \mathrm{~d}$ & $4.31 \pm 0.56^{\mathrm{bc}}$ & $3.43 \pm 0.43^{\mathrm{c}}$ & $4.60 \pm 0.31^{\mathrm{bc}}$ & $3.28 \pm 0.08^{\mathrm{c}}$ & $4.06 \pm 0.68^{\mathrm{a}}$ & $3.28 \pm 0.71^{\mathrm{a}}$ & $4.56 \pm 0.10^{\mathrm{a}}$ & $2.70 \pm 0.13^{\mathrm{c}}$ \\
\hline $8 \mathrm{~d}$ & $3.97 \pm 0.59^{\mathrm{bc}}$ & $3.53 \pm 0.46^{\mathrm{bc}}$ & $4.07 \pm 0.68^{\mathrm{c}}$ & $4.34 \pm 0.33^{\mathrm{bc}}$ & $3.56 \pm 0.28^{\mathrm{a}}$ & $5.01 \pm 1.19^{\mathrm{a}}$ & $3.51 \pm 0.74^{\mathrm{abc}}$ & $3.42 \pm 0.38^{\mathrm{abc}}$ \\
\hline $16 \mathrm{~d}$ & $7.19 \pm 1.19^{\mathrm{a}}$ & $5.61 \pm 0.86^{\mathrm{ab}}$ & $8.05 \pm 0.78^{\mathrm{a}}$ & $5.52 \pm 0.55^{\mathrm{b}}$ & $4.68 \pm 0.47^{\mathrm{a}}$ & $4.90 \pm 0.52^{\mathrm{a}}$ & $4.19 \pm 0.65^{\mathrm{ab}}$ & $4.08 \pm 0.14^{\mathrm{abc}}$ \\
\hline
\end{tabular}

Note. Table 3 represent the contents of the total flavonoids compounds (TFC) in the control (CK) and walnut fruits infected Xaj treated for $0-16$ days. And the values are expressed as the mean \pm standard deviation of three biological replicates. Letters indicated significant differences at a level of $p<0.05$.

\section{Analysis Of Monomer Phenol Contents}

After the treatments, the four cultivars showed different amounts of catechin, $p$-coumaric acid, gallic acid, protocatechuic acid, myricetin, quercetin, chlorogenic acid and ferulic acid. Some of these played a role in interactions between walnut fruits and pathogenic activity.

A significant decrease in gallic acid content was detected in 'Xiangling' and 'Xiluo 2' after the treatments. On the 8th dpi, the gallic acid content in 'Xiangling' began to decrease significantly, but still remained similar to the amount in control fruits. However, the gallic acid content in inoculated fruits of 'Xiluo 2 ' was always significantly lower than that of the control fruits, except that it neared the value of the gallic acid content in the control group on the. 'Yuanfeng' 
changed little throughout the period of observation. Surprisingly, the gallic acid content of the susceptible cultivar 'Xifu 2' increased slightly on the 8th day after inoculation. The results showed that gallic acid correlated weakly with disease resistance ( Figure S1).

The change in catechin content was not observed in 'Yuanfeng' and 'Xifu 2'. At 4 dpi, the catechin contents in 'Xiangling' and 'Xiluo 2' increased by $140 \%$ and 7.4-fold, respectively, and then decreased to their initial level. Inoculated fruits of 'Xiangling' had no obvious difference compared to the control fruits. However, inoculated fruits of 'Xiluo 2' showed that catechin contents were significantly lower than that of the control fruits (Figure S2). Furthermore, the amount of chlorogenic acid decreased rapidly in the inoculated 'Xifu 2' cultivar on the 4th dpi, but remained very close to the control samples. The other three cultivars showed no changes in this regard throughout the experiment. This observation suggested a weak interaction between chlorogenic acid and the pathogen (Figure S3). The amount of $p$-coumarin in 'Xiangling' increased in the later stage of inoculation, and was significantly higher than that of the control. Similarly, at $16 \mathrm{dpi}$, its content in the inoculated 'Yuanfeng' was significantly higher than that of the control and, on the 4th day, the amount of $p$-coumarin decreased significantly, so that its difference with the control was negligible. In 'Xiluo 2', however, no changes occurred in this respect as a result of inoculation (Figure S4).

While the amount of protocatechuic acid and ferulic acid were lower than other phenolic chemicals, their roles cannot be overlooked. On the 4th dpi, protocatechuic acid increased significantly in all cultivars. The protocatechuic acid content in 'Xiluo 2' became significantly higher than that of the control samples, indicating that this compound plays an important role in the early stage of disease resistance (Table 5). On the other hand, the maximum amount of ferulic acid was measured in the resistant cultivar after infection. At 4 dpi, ferulic acid increased substantially in the fruits of 'Xiangling' and 'Xiluo 2', while having a significant difference with the control fruits. Inoculated samples of 'Yuanfeng' staged a significant decrease in ferulic acid content on the 4th day, although their content became significantly higher than that of the control on the 8th day. Meanwhile, the 'Xifu 2' basically remained unchanged in this regard (Fig. 7).

Table 5

Content of Protocatechuic acid $\left(\mathrm{mg} \cdot \mathrm{g}^{-1} \mathrm{FW}\right)$

\begin{tabular}{|c|c|c|c|c|c|c|c|c|}
\hline \multirow[t]{2}{*}{ Days after treatments } & \multicolumn{2}{|l|}{ Xiangling } & \multicolumn{2}{|l|}{ Xluo 2} & \multicolumn{2}{|l|}{ Yuanfng } & \multicolumn{2}{|l|}{ Xifu 2} \\
\hline & CK & Xaj & CK & Xaj & CK & Xaj & CK & Xaj \\
\hline Od & $0.47 \pm 0.06^{b}$ & $0.53 \pm 0.04^{b}$ & $0.53 \pm 0.10^{c}$ & $0.62 \pm 0.01^{c}$ & $0.32 \pm 0.15^{\mathrm{b}}$ & $0.38 \pm 0.11^{\mathrm{b}}$ & & \\
\hline $4 d$ & $2.43 \pm 0.44^{\mathrm{a}}$ & $2.87 \pm 0.21^{\mathrm{a}}$ & $2.06 \pm 0.50^{\mathrm{b}}$ & $3.61 \pm 0.33^{\mathrm{a}}$ & $3.18 \pm 0.66^{\mathrm{a}}$ & $2.85 \pm 0.30^{\mathrm{a}}$ & $2.94 \pm 0.48^{a}$ & $3.07 \pm 0.52$ \\
\hline $8 d$ & $0.24 \pm 0.03^{b}$ & $0.24 \pm 0.07^{b}$ & $0.60 \pm 0.01^{c}$ & $0.65 \pm 0.08^{c}$ & $0.14 \pm 0.01^{\mathrm{b}}$ & $0.24 \pm 0.05^{\mathrm{b}}$ & $0.19 \pm 0.03^{b}$ & $0.19 \pm 0.00^{t}$ \\
\hline $16 d$ & $0.23 \pm 0.03^{b}$ & $0.23 \pm 0.02^{b}$ & $0.81 \pm 0.02^{c}$ & $0.47 \pm 0.12^{c}$ & & $0.16 \pm 0.02^{b}$ & $0.20 \pm 0.01^{b}$ & $0.36 \pm 0.02$ \\
\hline
\end{tabular}

\section{Discussion}

Despite their high monetary potential in production and nutritional value, walnut trees are susceptible to the occurrence of walnut blight disease which can restrict their economic output on a large scale. An illustration of the mechanism by which the walnut-pathogen interaction takes place can make significant contributions to basic research and breeding practice. In the current research, a series of changes were observed in the biochemical indexes of the four cultivars after exposure to pathogenic infection.

Phenolic compounds are found primarily in the cytoplasm and are separated from phenolase by the cell membrane system, meaning that phenolase does not come into direct contact with phenolic compounds. When plants are invaded by pathogens, the cell membrane system is destroyed and, thus, phenolic compounds can be released. This makes them have toxic effects through their conversion to phytoalexins and free radicals that originate in lignin precursors [24]. It has long been realized that the response of plants to pathogens is featured by the early accumulation of phenolic compounds at the infection site, and that pathogens develop limitedly [25]. In our results, the TPC in 'Xiangling' and 'Xiluo 2' increased significantly on the 4th day. This phenomenon can explain that plant defense in walnut reacts to pathogens by an early accumulation of phenolic compounds. Phenolic accumulation is an initial response to inoculated pathogens and may reflect an increase in relatively nontoxic secondary metabolites, which eventually serve as precursors that bring on plant resistance [26]. In this regard, our results showed a remarkable accumulation of protocatechuic acid on the 4th dpi in both resistant and susceptible cultivars.

Interestingly, the amount of protocatechuic acid in 'Xiluo 2' was significantly higher than that of the control at 4 dpi. According to previous findings by Liu et al. [27], protocatechuic acid effectively inhibited the growth of pathogens in the said research. Furthermore, protocatechuic acid is reportedly a precursor to gallic acid [28]. It can be synthesized through ferulic acid and vanillic acid in the transformation pathway of lignin-derived monomers [29]. Chlorogenic acid is a phenol molecule that has an ortho-dihydroxy group in its structure. In a previous study by Gauthier et al. [30], it was confirmed that pathogenic infection can lead to the degradation of chlorogenic acid into caffeic and protocatechuic acids. In the current study, however, the amount of chlorogenic acid remained high and did not participate in disease-resistance as a response. In part, the reason is that chlorogenic acid remains as a reservoir of caffeoyl moiety and subverts into the synthesis of other phenolic compounds. A lack cumulative resistance can emanate from interactions between biochemical compounds and direct transformations from phenylpropane coenzyme A esters to other phenols, especially since the latter contribute more to defense-response [26]. It is evident that the synthesis and transformation of phenols are extremely complex, and that precise synthetic pathways through molecular interactions are subjects of ongoing research. 
The accumulation of phenols in the infection site, caused by pathogenic bacteria, not only strengthened the cell wall structure but was also accompanied by the accumulation of reactive oxygen species, which promoted cross-linking reactions within the cell wall. A study revealed that the production of a phenolic conjugate - feruloyltyramine - can be induced by the HRP gene in pepper to induce resistance against Xanthomonas campestris [31]. POD is not only the primary enzyme for $\mathrm{H}_{2} \mathrm{O}_{2}$ decomposition, but it can also catalyze the dimerization of ferulic acid. The occurrence of free radical coupling, as a reaction that involves ferulic acid residues, can strengthen the early structure of cell walls in association with phenolic cross-linking of hemicellulose via dicarboxylic acid. This is followed by the synthesis of phenolic monomers or by lignification which contributes to plant resistance against disease[32-33]. On the 4th dpi, POD activity and ferulic acid content increased significantly in 'Xiluo 2', indicating that POD catalyzes ferulic acid in an effort to act against pathogens.

PAL is a general measure of phenolic synthesis after infection. Through a comprehensive transcriptome and metabolome analysis, Li et al. [34] confirmed that the involvement of metabolites in phenylpropane biosynthesis relates closely to plant resistance against Zanthoxylum bungeanum which causes stem canker. The enzymatic step of this pathway is the conversion of L-phenylalanine to cinnamic acid by PAL, followed by $p$-coumaryl-CoA. When compounds have been derived from this pathway, they originate from this branching point through the action of chalcone synthase (CHS) for the synthesis of flavonoids [35-36]. Since the VqMYB154 gene reportedly increased STS expression in wild grapes, plant interaction with pathogens caused a decrease in $C H S$ competitiveness and promoted stilbene accumulation, thereby assisting plant resistance [37]. In our results, there was no significant difference in the TFC after inoculation except that 'Xiluo 2' and 'Xifu 2' had significantly lower levels of this value, compared to the control, when observed in different time periods. The reason for this may be a decrease in the competitiveness of flavonoids in biosynthesis, thereby promoting the resistance caused by chemicals that are catalyzed by PAL and, thus, act against walnut blight. In the current study, PAL activity increased in response to infection, and was significantly higher than that of the control at different stages of disease development. Previous research showed that pathogenic activity can lead to the accumulation of salicylic acid in infected tissues and, moreover, a role exists between PAL activity and pathogen-induced salicylic acid formation in many plants [38]. The resistance caused by salicylic acid against walnut blight can be studied further.

PPO is a nuclear-encoded and plastid copper-containing enzyme that catalyzes the oxidation of oxygen-dependent phenolic compounds to o-diquinones. Its quinone products are highly-active molecules that can modify and crosslink nucleophilic molecules covalently against pathogens [39]. The highest expression levels of PPO are usually recorded in young tissues such as new leaves and fruits, which are particularly vulnerable to disease [40]. According to a relevant study, walnut blight disease induced the expression of JrPPO1 and PPO activity [41]. In the later stages of pathogenic development, however, PPO activity in all infected plants became significantly higher than that of the control, suggesting that PPO may be an indirect regulator of cell death in walnut and may result in necrotic spots on the fruits [14]. At the same time, it can play a series of defense-related functions with ROS. At the time of pathogenic invasion, the direct toxicity of quinone mediated covalent modification in macromolecules and caused the direct antimicrobial toxicity of $\mathrm{H}_{2} \mathrm{O}_{2}$ which limited the progress of disease. The cross-linking of oxidative phenols and the formation of lignin tend to produce a physical barrier against pathogens [40]. The accumulation of ROS in resistant tissues is considered to be the main mechanism of killing or inhibiting pathogens [41]. Among the different types of ROS, superoxide (02. ${ }^{-}$) and $\mathrm{H}_{2} \mathrm{O}_{2}$ are involved functionally in plant resistance against numerous diseases [42]. CAT is one of the primary systems in plants that can enable the enzymatic hydrolysis of $\mathrm{H}_{2} \mathrm{O}_{2}$ molecules. In our study, CAT and PPO activities in 'Yuanfeng' and 'Xifu 2' were significantly higher than those of the control at the later stages of pathogenic development, which demonstrated the involvement of enzymes in countering pathogenic activity and ROS toxicity. SOD is known to function in association with ROS and, thus, can act against plant disease [42]. In all cultivars of the current study, on the 4th dpi, SOD activity had a significant increase in infected samples, compared to control samples, indicating the interaction between SOD and walnut blight at the early stage of inoculation. It was observed that the SOD content increased by 1.58 -fold in the susceptible cultivar 'Xifu 2', far exceeding that of the resistant cultivar, partly because a high accumulation of SOD occurred in infected samples, compared to uninfected samples. SOD assisted in the removal of reactive oxygen species after pathogenic invasion, thereby prompting infected tissues to show fewer symptoms.

\section{Conclusion}

Taken together, a resistant walnut cultivar was identified against Xanthomonas. By determining the biochemical reactions that associated with plant responses to the pathogen, the results showed that relevant defense enzymes and phenols were involved in the interaction between walnut and Xanthomonas. Our results provided important information on physiological aspects in walnut that induce resistance to walnut blight. Since reactions between the host and pathogenic microorganisms are highly complicated, it is recommended that future studies consider how a series of phenolic compounds can mediate plant resistance in the metabolic process through the phenylpropane pathway.

\section{Methods}

\section{Experimental site and plant material}

This study used four walnut cultivars: 'Xiangling', 'Xiluo 2', 'Yuanfeng' and 'Xifu 2'. The Walnut Demonstration Station at Northwest A\&F University in Shanyang was the location of sampling healthy and undamaged walnut fruits $\left(33.20^{\circ} \mathrm{N}, 109.50^{\circ} \mathrm{E}\right)$. The station has an altitude of 1100 meters, an annual average precipitation of $709 \mathrm{~mm}$, an average temperature of $13.1^{\circ} \mathrm{C}$ and an average frost-free period of 207 days. The station is located in a temperate, moist, mountainous climate zone.

\section{Field Investigation}

We observed the occurrence of walnut blight disease among the four cultivars, i.e. 'Xiangling', 'Xiluo 2', 'Yuanfeng' and 'Xifu 2' in the field and, in the beginning, a 5-point sampling method was used for evaluating 20 walnut trees at random per cultivar. The disease grade was determined by counting the number of lesions on walnut fruits in the whole tissue and calculating the disease index. Grade 0 had no disease; grade 1 meant lesions that accounted for less than $1 / 4$

Page 6/13 
of the whole fruit surface; grade 2 meant lesions that accounted for 1/4-1/2 of the whole fruit surface; grade 3 accounted for $1 / 2-3 / 4$ of the fruit surface; and grade 4 accounted for more than $3 / 4$.

Disease index $(\mathrm{Di})=\Sigma$ (number of diseased walnut at all grades $) \times($ Representative value at all grades $) /($ total number of investigated walnut $\times 4) \times 100$.

The criteria for evaluating cultivar resistance were scaled in ranges that varied. Di $\leq 25$ represented resistance, $25<\mathrm{Di} \leq 40$ moderate resistance, $40<\mathrm{Di} \leq 55$ moderate susceptibility, and $\mathrm{Di}>55$ susceptibility [43].

\section{Isolation and identification of Xanthomonas}

The Xaj-417 strain was isolated and identified from disease-infected walnut fruits in Yangling, Shaanxi. First, $0.5 \times 0.5 \mathrm{~cm}$ samples were taken from the intersection of diseased and healthy tissue. The tissue was then disinfected in $2 \% \mathrm{NaClO}$ for 1-2 min before being rinsed in sterile water for 2-3 times before drying it [44]. The tissue was placed in LB solid medium at $28^{\circ} \mathrm{C}$ (Fig. 8a). The yellow, convex, small bacterial colonies can be observed in Figure $8 \mathrm{~b}$. The DNA was extracted after a single colony was cultured in LB liquid medium. To extract bacterial DNA groups, the Ezup Column Bacteria Genomic DNA Purification Kit was used (Sangon Biotech, Shanghai). PCR amplification of the bacterial genome operated according to previous research by Kim et al. [45]. The primers 27F: 5'-AGAGTTTGATCMTGGCTCAG-3', 1492R: 5'-GGTTACCTTGTTACG ACTT -3' were synthesized by Sangon Biotech. The results of two-way sequencing were made on Sangon Biotech among the PCR products and were used from a published reference on the NCBI website (http://www.ncbi.nlm.nih.gov). The reference number for NCBI was CP012251.1.

\section{Pathogenicity Determination}

Pathogenicity determination

The Xaj-417 strain was stored at $-80^{\circ} \mathrm{C}$ and cultured in liquid LB medium at $28^{\circ} \mathrm{C}$. The bacterial concentration was adjusted to $10^{8} \mathrm{CFU} \mathrm{mL}^{-1}$ in sterile water before being applied on healthy walnut fruits for their inoculation. Stab inoculation was carried out as a method, according to Kim et al. [45], with some modifications. The 60 days walnut fruits after pollination were selected for studies on pathogenic infection. First, we performed a $0.5 \times 0.5 \mathrm{~cm}$ stab on the surface of fruits to cause infection by bacteria in the syringe. The same fruits were treated with sterile water as the control. The filter paper was then moistened with $1 \mathrm{~mL}$ sterile water in the transparent valve bag. After the treatments, the fruits were sampled on days $0,4,8$, and 16 after the treatment for further analysis. There were 48 fruits per cultivar and three biological replicates were performed for each treatment. The number of infected sites was calculated using the infection incidence (\%) on the 16th day. The average blight area was used in calculating the size of the fruit lesion.

\section{Antioxidant Enzyme Extraction And Activity Determination}

A precooled mortar containing $4 \mathrm{~mL}$ phosphate buffer $(100 \mathrm{mM}, \mathrm{pH}=7.8), 0.5$ percent Triton-100, and $0.1 \mathrm{~g}$ PVPP was used for grinding 60-day-old fresh walnut fruits $(0.5 \mathrm{~g})$. Then, the samples were ground and homogenized, while the temperature was maintained at $4^{\circ} \mathrm{C}$ overnight. The solution was centrifuged for 15 minutes at $10000 \mathrm{rpm}$ at $4^{\circ} \mathrm{C}$ [46]. The enzyme extract remained constant at $4^{\circ} \mathrm{C}$ to determine the amounts of SOD, CAT and POD. Specifically, the SOD activity was determined by the NBT photoreduction method, using an amount of enzyme that could inhibit $50 \%$ of the NBT photoreduction reaction as one

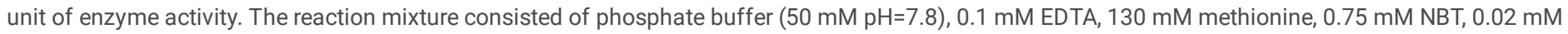
riboflavin [47]. CAT activity was determined according to a method by Gao [48]. Phosphate buffer ( $50 \mathrm{mM}, \mathrm{pH}=7.0)$ was used in association with $200 \mathrm{mM}$ $\mathrm{H}_{2} \mathrm{O}_{2}$. The absorbance decreased at $240 \mathrm{~nm}$ by 0.1 at a rate of 1 minute per unit of enzyme activity. The Guaiacol method, which included phosphate buffer (200 mM, pH = 7.0), $50 \mathrm{mM}$ Guaiacol solution and $0.03 \% \mathrm{H}_{2} \mathrm{O}_{2}$ was used for determining POD activity. The reaction solution was mixed with the enzyme extract and allowed to react at $37^{\circ} \mathrm{C}$ for 5 minutes. The absorbance at $470 \mathrm{~nm}$ was measured immediately after the reaction [48].

\section{Pal Extraction And Activity Determination}

In the PAL extraction solution, $3 \mathrm{~mL}$ boric acid buffer $(50 \mathrm{mM}, \mathrm{pH}=8.8)$ was used in association with $5 \mathrm{mM} \beta$-Mercaptoethanol, $1 \mathrm{mM}$ EDTA and $2 \%$ PVP. With the enzyme solution $(0.5 \mathrm{~mL}), 1 \mathrm{~mL}$ of $\mathrm{L}$-phenylalanine $(10 \mathrm{mM})$ and $1.5 \mathrm{~mL}$ of boric acid buffer $(100 \mathrm{mM}, \mathrm{PH}=8.8)$ were used for rendering the reaction operative at $37^{\circ} \mathrm{C}$ for $1 \mathrm{~h}$. Then, the reaction was terminated by adding $0.2 \mathrm{~mL}$ of $\mathrm{HCl}\left(6 \mathrm{~mol} \cdot \mathrm{L}^{-1}\right)$ and the amount of enzyme required for changing the absorbance by 0.01 (at $290 \mathrm{~nm}$ per hour) was defined as one unit of enzyme activity [48].

\section{Ppo Extraction And Activity}

The PPO solution for extraction contained $3 \mathrm{~mL}$ Tris buffer $\left(50 \mathrm{mmol} \cdot \mathrm{L}^{-1}, \mathrm{pH}=8.3\right), 1 \%$ (W/V) PEG 8000, 11\% (V/V) glycerol, $0.015 \%$ (W/V) citric acid monohydrate and $0.010 \%(\mathrm{~W} / \mathrm{V})$ cysteine monohydrate, $0.01 \%(\mathrm{~W} / \mathrm{V})$ ascorbic acid [49]. The assay solution comprised $5 \mathrm{mg} / \mathrm{mL} \mathrm{L}-\mathrm{Dopa}$ in $1.4 \mathrm{~mL}$, which consisted of $\mathrm{Na}_{2} \mathrm{HPO}_{4}(100 \mathrm{mM}, \mathrm{pH}=7.0), 0.015 \%$ (w/v) sodium dodecyl sulfate and $280 \mathrm{U} \mathrm{mL}^{-1}$ catalase. The absorbance was measured at $490 \mathrm{~nm}[50]$.

\section{Chemical Extraction And Determination}


Phenolic compounds were extracted from walnut fruits using an ultrasonic method and a solvent of $50 \%$ methanol (V/V) by Shi et al. [51]. Accordingly, $0.5 \mathrm{~g}$ fresh fruit was mixed with $2 \mathrm{~mL}$ methanol and was ground to a homogenate texture. The supernatant was centrifuged at 10,000 rpm for $30 \mathrm{minutes}$ before being placed in a $0.5 \mathrm{~h}$ ultrasonic bath at $40^{\circ} \mathrm{C}$. The residue was then treated with $2 \mathrm{~mL}$ of methanol, and the procedure was repeated. The extracting solution was kept at $4^{\circ} \mathrm{C}$ until further analysis.

Determining the TPC and TFC followed a method previously described by Skerget et al. [52] The monomer phenol was determined by passing 1 mL of the extracting solution through a $0.22 \mu \mathrm{M}$ filter membrane and into a chromatographic flask. The HPLC analysis was performed on an Agilent Infinity Lab HPLC System with a thermostat configured at $25^{\circ} \mathrm{C}$. The mobile phase was ultrapure water, with $0.1 \%(\mathrm{v} / \mathrm{v})$ formic acid (eluent $\left.\mathrm{A}\right)$ and $0.1 \%(\mathrm{v} / \mathrm{v})$ formic acid acetonitrile (eluent B) [53]. All samples received an injection volume of $5 \mu \mathrm{L}$. The flow rate was $0.5 \mathrm{~mL} / \mathrm{min}$, and the gradient programs ran on a pattern of 10\% 25\% B (0-10 min), 25\% 60\%B (10-25 min), 60\% B (25-35 min), and 60\% 10\% B (35-40 min). At $280 \mathrm{~nm}$, Catechin, p-coumaric acid and gallic acid were detected. At $250 \mathrm{~nm}$, however, protocatechuic acid, myricetin, juglone and quercetin were detected. Meanwhile, chlorogenic acid and ferulic acid were detected at $320 \mathrm{~nm}$.

\section{Statistical analysis}

For statistical analysis, the SAS (Institute, Cary, NC; 1996) statistical software package was used. The data were calculated and displayed as mean values \pm SD. The data were analyzed by LSD $(p<0.05)$.

\section{Abbreviations}

\section{Catalase}

CAT

Day after inoculation

Dpi

Dibasic sodium phosphate

$\mathrm{Na}_{2} \mathrm{HPO}_{4}$

Ethylene diamine tetraacetic

EDTA

High performance liquid chromatography

HPLC

Hydrochloride

$\mathrm{HCl}$

L-3,4 dihydroxyphenylalanine

\section{L-Dopa}

Nitrotetrazolium blue chloride

NBT

Nicotinamide adenine dinucleotide phosphate

$\mathrm{NADPH}$

Hydrogen peroxide

$\mathrm{H}_{2} \mathrm{O}_{2}$

Polyethylene glycol

PEG

Peroxidase

POD

Phenylalanine ammonia lyase

PAL

Polyphenol oxidase

PPO

Polyvinyl pyrrolidone

PVP

Crosslinked polyvinyl pyrrolidone

PVPP

Reactive oxygen species

ROS

Respiratory burst oxygenase homologs

RBOHs

Sodium hypochlorite solution

$\mathrm{NaClO}$

Superoxide dismutase SOD

Total phenol content

TPC 
Total flavonoid content

TFC

Xanthomonas arboricola pv. Juglandis

Xaj.

\section{Declarations}

\section{Acknowledgments}

We thank College of Forestry, Northwest A\&F University and Walnut Demonstration Station in Shanyang for kindly providing the fruits of walnut.

\section{Statement}

We have obtained permissions to collect walnut cultivars and confirmed that all methods were performed in accordance with the relevant guidelines and regulations.

\section{Funding}

The present work was funded by National natural science committee, grant number "31670650" and Northwest A \& F University, grant number "TGZX2020$05^{\prime \prime}$.

\section{Ethics approval and consent to participate}

Not applicable.

\section{Consent for publication}

Not applicable.

\section{Competing interests}

The authors declare no conflict of interest.

\section{References}

1. Jahanbani R., Ghaffari SM, Salami S, Vahdati K, Sepehri H, Sarvestani NN, Sheibani NAntioxidant and anticancer activities of walnut (Juglans regia L.) protein hydrolysates using different protease. Plant Foods Hum Nutr. 2016;71(4):402-409.

2. Belisario A, Zoina A, Pezza L, Luongo L. Susceptibility of species of Juglans to pathovars of Xanthomonas campestris. Eur J For Path. 1999;29(1):75-80.

3. Loreti S, Gallelli A, Belisario A, Wajnberg E, Corazza L. Investigation of genomic variability of Xanthomonas Arboricola juglandis by AFLP analysis. Eur J Plant Pathol. 2001;107(6):583-591.

4. An HS, Yang KQ. Sequence Analysis of NBS-type RGAs and Their relationship with anthracnose resistance in walnut. Scientia Agricultura Sinica. 2014;47(2):344-356.

5. Lindow S, Olson W, Buchner R. Colonization of dormant walnut buds by Xanthomonasarboricola pv. juglandis is predictive of subsequent disease. Phytopathology. 2014;104(11): 1163-1174.

6. Zhang F, Hu ZQ, Wu ZC, Lu JL, Shi YY, X JL, Wang XY, Wang JP. Reciprocal adaptation of rice and Xanthomonas oryzae pv. oryzae: cross-species 2D GWAS reveals the underlying genetics. Plant Cell. 2021;33(8):2538-2561.

7. Islam MN, Ali MS, Choi SJ, Hyun JW, Baek KH. Biocontrol of citrus canker disease caused by Xanthomonas citri subsp. citri using an endophytic bacillus thuringiensis. Plant Pathology J. 2019; 35(5):486-497.

8. Gent DH, Schwartz HF. Management of Xanthomonas leaf blight of onion with a plant activator, biological control agents, and copper bactericides. Plant Dis. 2005;89(6):631-639.

9. Giovanardi D, Bonneau S, Gironde S, Saux FL, Manceau C, Stefani E. Morphological and genotypic features of Xanthomonas arboricola pv. juglandis populations from walnut groves in Romagna region, Italy. Eur J For Path. 2015;145(1):1-16.

10. Xie H, Wang Y, Liu YQ, and Chen LP. The influence of plant constitutive defense system on phytophagous insects. Plant Protection. 2012;38(1):1-5.

11. Zhang QH, Li XM, Long XY, Hu BY, Xiao XL, Zhang XW, TAKPAH D, Yang CQ, Yang WY, Liu J. Metabolism of the cutin and wax of plants and their disease resistance mechanism. Journal of Zhejiang A\&F University. 2020;37(6):1207-1215.

12. Umesha S. Phenylalanine ammonia Lyase activity in tomato seedlings and its relationship to bacterial canker disease resistance. Phytoparasitica. 2006;34(1):68-71.

13. Aaron B, Ron M, Nobuhiro S. ROS as key players in plant stress signalling. J Exp Bot. 2014;65(5):1229-1240.

14. Jiang SJ, Han S, He D, Cao GL, Fang K, Xu X, Yi JM, Wan XQ. The accumulation of phenolic compounds and increased activities of related enzymes contribute to early defense against walnut blight. Physiol Mol Plant P. 2019;108:101433.

15. Qi JS, Wang JL, Gong ZZ, Zhou JM. Apoplastic ROS signaling in plant immunity. Curr Opin Plant Biol. 2017;38:92-100. 
16. Hua XY, Tao S, Sun SN, Guo, Yan XF, Lin JX. Research progress on phenolic compounds of plant secondary metabolites. Biotechnology Bulletin. 2017;33(12):22-29.

17. Wu ST, Shen DY, Wang RH, Li QY, Mo RH, Zheng YW, Zhou Y, Liu YHI. Phenolic profiles and antioxidant activities of free, esterified and bound phenolic compounds in walnut kernel. Food Chem. 2021;350: 129217.

18. Cheniany M, Ebrahimzadeh H, Vahdati K, Preece JE, Masoudinejad A, Mirmasoumi M. Content of different groups of phenolic compounds in microshoots of Juglans regia cultivars and studies on antioxidant activity. Acta Physiol Plant. 2013;35(2): 443-450.

19. Henry-Kirk RA, McGhie TK, Andre CM, Hellens RP, Allan AC. Transcriptional analysis of apple fruit proanthocyanidin biosynthesis. J Exp Bot. 2012;63(15): 5437-5450.

20. Kumar A, Hunjan MS, Kaur H, Dhillon HK, Singh PP. Biochemical responses associated with resistance to bacterial stalk rot caused by Dickeya zeae in maize. J Phytopathol. 2017;165(11-12):822-832.

21. Guo GY, Bai F, Liu W, Bi CL. Advances in research of the regulation of transcription factors of lignin biosynthesis. Scientia Agricultura Sinica. 2015;48(7): 1277-1287.

22. Zhao SG, Wang HX, Liu K, Li LQ, Yang JB, An XH, Li PP, Yun LY, Zhang ZH.The role of JrPPOs in the browning of walnut explants. BMC Plant Biol.2021;21(9).

23. Thipyapong P, Stout MJ, Attajarusit J. Functional analysis of polyphenol oxidases by antisense/sense technology. Molecules. 2007;12(8): 1569-1595.

24. Richard-N B, Roger-M W. Secondary metabolites in plant defence mechanisms. New Phytol. 1994;127:617-633.

25. Boubakri, H, Poutaraud A, Wahab MA,Clayeux C, Baltenweck-Guyot R, Steyer D, Marcic C, Mliki A, Soustre-Gacougnolle, I. Thiamine modulates metabolism of the phenylpropanoid pathway leading to enhanced resistance to Plasmopara viticola in grapevine. BMC Plant Biology. 2013;13:31.

26. Nicholson RL, Hammerschmidt R. Phenolic compounds and their role in disease resistance. Annu Rev Phytopathol. 1992;30:369-389.

27. Liu, KS, Tsao SM, Yin MC. In vitro antibacterial activity of roselle calyx and protocatechuic acid. Phytother Res. 2010;19(11):942-945.

28. Bruckner C, Oreb M, Kunze G, Boles E, Tripp J. An expanded enzyme toolbox for production of cis, cis-muconic acid and other shikimate pathway derivatives in Saccharomyces cerevisiae. FEMS Yeast Res. 2018;18(2): foy017.

29. Okai N, Masuda T, Takeshima Y, Tanaka K, Yoshida K, Miyamoto M, Ogino C, Kondo A. Biotransformation of ferulic acid to protocatechuic acid by Corynebacterium glutamicum ATCC 21420 engineered to express vanillate O-demethylase. AMB Express. 2017;7: 130.

30. Gauthier L, Bonninverdal MN, Marchegay G, Pinsongadais L, Ducos C, Richard-Forget F, Atanasova-penichon V. Fungal biotransformation of chlorogenic and caffeic acids by Fusarium graminearum: New insights in the contribution of phenolic acids to resistance to deoxynivalenol accumulation in cereals. Int J Food Microbiol. 2016;221:61-68.

31. Newman MA, Roepenack-Lahaye E, Parr A, Daniels MJ, Dow JM. Induction of hydroxycinnamoyl-tyramine conjugates in pepper by Xanthomonas campestris, a plant defense response activated by hrp gene-dependent and hrp gene-independent mechanisms. Mol Plant Microbe In. 2001;14(6):785792.

32. Weber B, Hoesch L, Rast DM. Protocatechualdehyde and other phenols as cell wall components of grapevine leaves. Phytochemistry. $1995 ; 40(2): 433-437$.

33. Lee BR, Kim KY, Jung WJ, Avice JC, Ourry A, Kim TH. (2007). Peroxidases and lignification in relation to the intensity of water-deficit stress in white clover (Trifolium repens L.). J Exp Bot. 2007;58(6): 1271-1279.

34. Li PQ, Zhao R, Fei ZX, Yan JJ, Tang GH. Integrated transcriptome and metabolome analysis revealed that flavonoid biosynthesis may dominate the resistance of Zanthoxylum bungeanum against stem canker. J Agr Food Chem. 2021;69(22): 6360-6378.

35. Rahioui B,Aissam S, Messaouri H, Moukhli A, Khadari B, El Modafar C. Roleof phenolic metabolism in the defense of the olive-tree against leaf-spot disease caused by Spilocaea oleaginae. INT J AGRIC BIOL. 2013;15(2):273-278.

36. Barros J, Serrani-Yarce JC, Chen F, Baxter D, Venables BJ, Dixon RA. Role of bifunctional ammonia-lyase in grass cell wall biosynthesis. Nat Plants. 2016;2(6): 16050.

37. Jiang CY, Wang D, Zhang J, Xu Y, Zhang CH, Zhang JX, Wang XP, Wang YJ. VqMYB154 promotes polygene expression and enhances resistance to pathogens in Chinese wild grapevine. Hortic Res-Englang. 2021;8(1):151.

38. Malamy J, Carr JP, Klessig DF, Raskin I. Salicylic Acid: A likely endogenous signal in the resistance response of tobacco to viral infection. Science. 1990;250(4983):1000-1002.

39. Li L, Steffens JC. Over expression of polyphenol oxidase in transgenic tomato plants results in enhanced bacterial disease resistance. Planta. 2002;215(2):239-247.

40. Thipyapong P, Melkonian J, Wolfe DW, Steffens JC. Suppression of polyphenol oxidases increases stress tolerance in tomato. Plant Sci. 2004;167(4):693703.

41. Bacsó R, Hafez YM, Király Z, Király L. Inhibition of virus replication and symptom expression by reactive oxygen species in tobacco infected with Tobacco mosaic virus. Acta Phytopathologica et Entomologica Hungarica. 2011;46(1): 1-10.

42. Albert1 R, Kunstler A, Lantos F, Ádám AL, Kiály L. Graft-transmissible resistance of cherry pepper (Capsicum annuum var. cerasiforme) to powdery mildew (Leveillula taurica) is associated with elevated superoxide accumulation, NADPH oxidase activity and pathogenesis-related gene expression. Acta Physiol Plant. 2017;39(2):53.

43. Gan L, Dai YL, Lu XS, Teng ZY, Chen W, Yang XJ. Seasonal epidemic dynamics and chemical control of leaf spot disease on fresh corn in the mountain area of the south Fujian. Plant Protection. 2021;47(6):213-222+230.

44. Fang, ZD. Research methods in plant disease. Beijing: China Agriculture Press. 1998. 
45. Kim HS, Cheon W, Lee Y, Kwon HT, Seo ST, Balaraju K, Jeon Y. Identification and characterization of Xanthomonas arboricola pv. juglandis causing bacterial blight of walnuts in Korea. Plant Pathol J. 2021;37(2): 137-151.

46. Min-Ni KD, James-M T, Peter-H Q. GT-2: in vivo transcriptional activation activity and definition of novel twin DNA binding domains with reciproca1 target sequence selectivity. Plant Cell. 1996;8(6):1041-1059.

47. Jetiyanon, K. Defensive-related enzyme response in plants treated with a mixture of Bacillus strains (IN937a and IN937b) against different pathogens. Biol Control. 2007;42(2):178-185.

48. Gao, JF. Experimental guidance for plant physiology. Beijing: Higher Education Press. 2006.

49. Matthew-A E, Andrew S. Characterization of polyphenol oxidase from wwalnut. J Am Soc Hortic Sci. 2008;133(6):852-858.

50. Constabel CP, Ryan CA. A survey of wound-and methyl jasmonate-induced leaf polyphenol oxidase in crop plants. Phytochemistry. 1998;47(4):507-511.

51. Shi BB, Zhang WN, Li X, Pan XJ. Seasonal variations of phenolic profiles and antioxidant activity of walnut (Juglans sigillata Dode) green husks. Int $\mathrm{J}$ Food Prop. 2018;20:S2635-S2646.

52. Skerget M, Kotnik P, Hadolin M, Hras AR, Simonic M, Knez Z. Phenols, proanthocyanidins, flavones and flavonols in some plant materials and their antioxidant activities. Food Chem. 2005;89(2):191-198.

53. Solar A, Jakopic J, Miklavc J, Stampar F, Veberic R., Trdan S. Walnut husk fly substantially affects sensory attributes and phenolic contents of the kernels in common walnut. Sci Hortic-Amsterdam. 2019;247:17-26.

\section{Figures}

\section{Figure 1}

Infection incidence of four cultivars on the 16th day postinoculation (dpi). The values are expressed as the mean \pm standard deviation of three biological replicates. Letters indicated significant differences at a level of $p<0.05$.

Figure 2

Average lesion caused by Xaj in fruits on the 16th day. The values are expressed as the mean \pm standard deviation of three biological replicates. Letters indicated significant differences at a level of $p<0.05$.

\section{Figure 3}

Effects of infection with Xaj and control (CK) on CAT activity in four cultivars during 0-16 day. The values are expressed as the mean \pm standard deviation of three biological replicates. Letters indicated significant differences at a level of $p<0.05$.

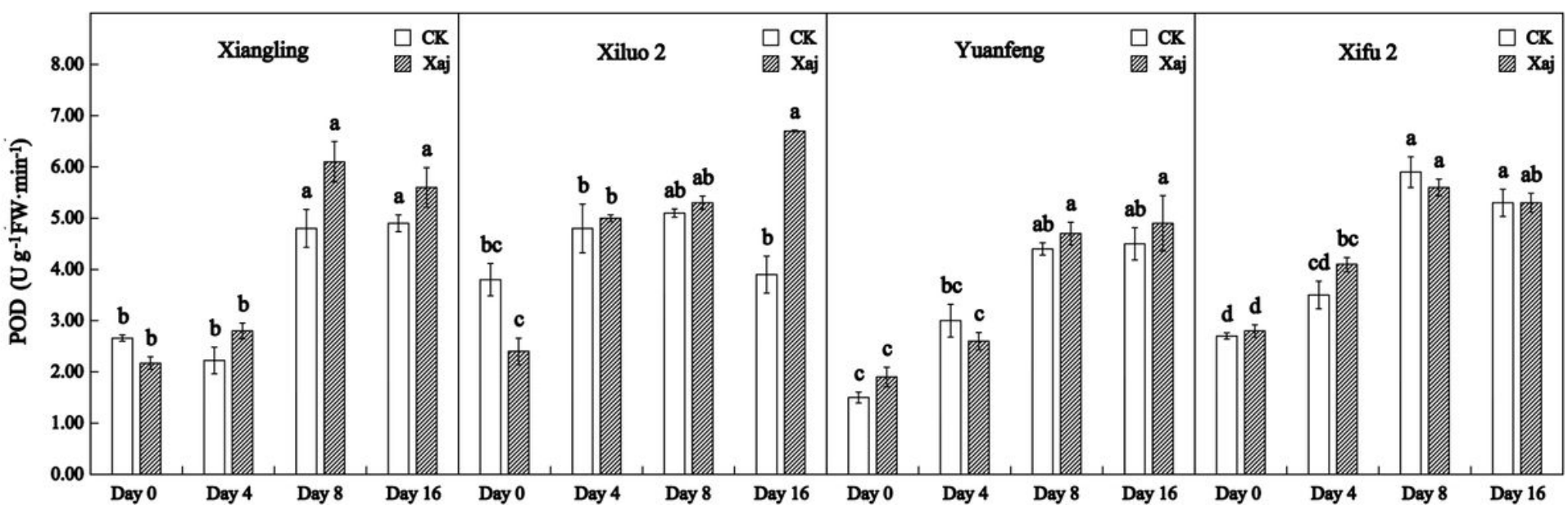

Figure 4

Changes in POD activity in the control (CK) and inoculated walnut fruits (Xaj) from 0 to 16 days. And the values are expressed as the mean \pm standard deviation of three biological replicates. Letters indicated significant differences at a level of $p<0.05$. 
Changes in PAL activity in the control (CK) and inoculated walnut fruits (Xaj) from 0 to 16 days. And the values are expressed as the mean \pm standard deviation of three biological replicates. Letters indicated significant differences at a level of $p<0.05$.

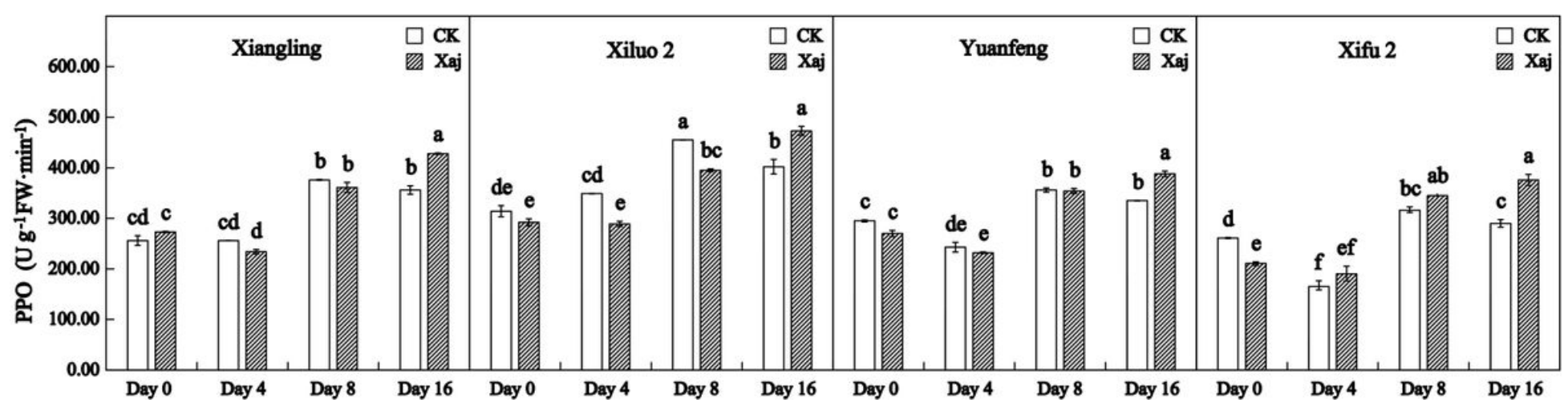

Figure 6

Changes in PPO activity in the control (CK) and inoculated walnut fruits (Xaj) from 0 to 16 days. And the values are expressed as the mean \pm standard deviation of three biological replicates. Letters indicated significant differences at a level of $p<0.05$.

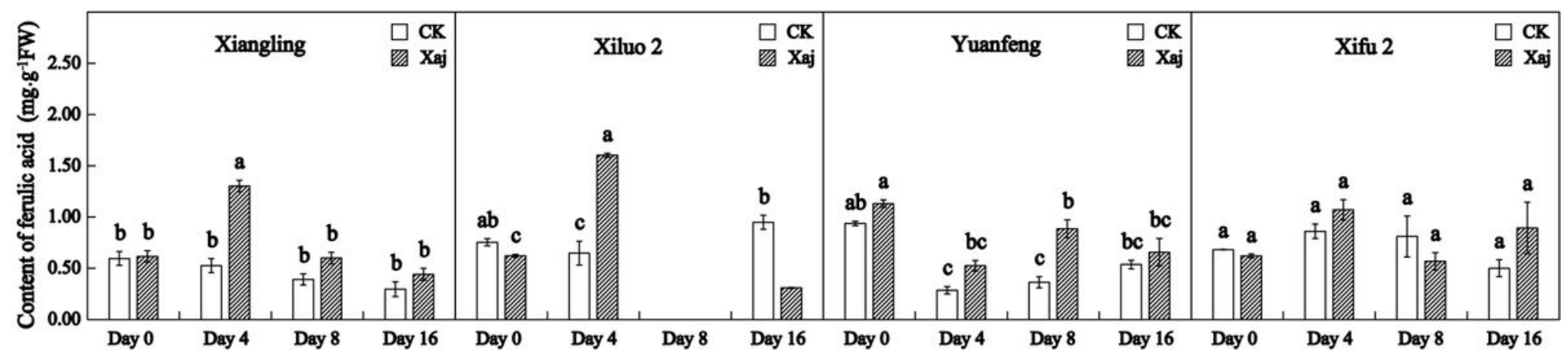

Figure 7

Effect of ferulic acid in the control (CK) and inoculated walnut fruits (Xaj) during 0-16 days. The blank histogram indicates that the content is too weak to detect. And the values are expressed as the mean \pm standard deviation of three biological replicates. 


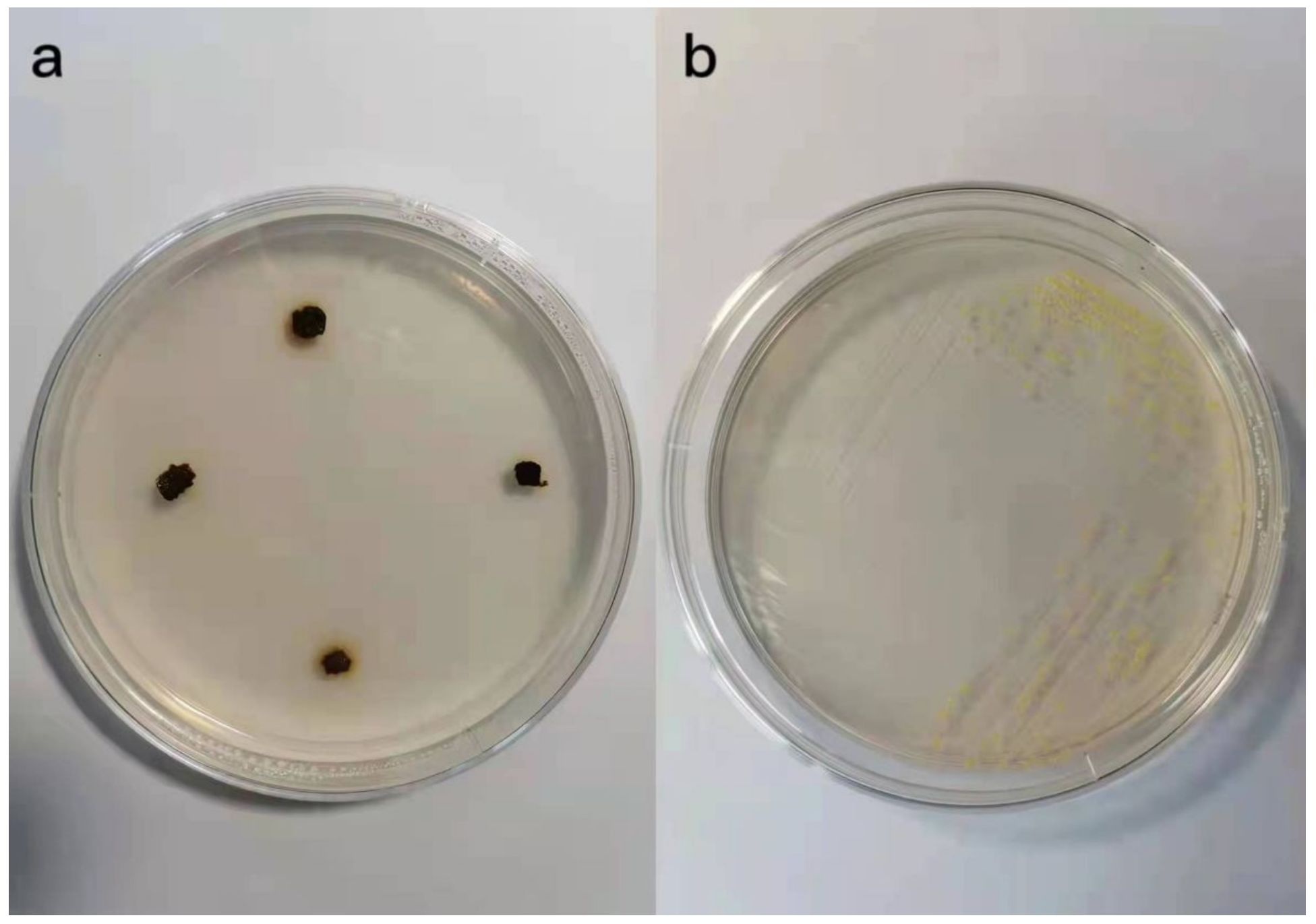

\section{Figure 8}

(a) Isolation of walnut blight diseased fruit; (b) Growth of bacteria on LB solid medium after 2 days of culture.

\section{Supplementary Files}

This is a list of supplementary files associated with this preprint. Click to download.

- supplementary.docx 